\title{
Vorsorge für allgemeine Bankrisiken
}

\begin{tabular}{|c|c|c|}
\hline & $\begin{array}{c}\text { Stille Vorsorgereserven } \\
(\S 340 \mathrm{HGB})\end{array}$ & $\begin{array}{c}\text { Offene Vorsorgereserven } \\
(\S 340 \mathrm{~g} \mathrm{HGB})\end{array}$ \\
\hline Zweck & \multicolumn{2}{|c|}{$\begin{array}{l}\text { Vorsorge für allgemeine Bankrisiken wie } \\
\text { - nicht bewertbare Kreditausfallrisiken } \\
\text { - Liquiditätsrisiken } \\
\text { - Zinsänderungsrisiken } \\
\text { - Wertpapierkursrisiken (insbesondere durch die Bewertung } \\
\text { der Wertpapiere des Handelsbestandes zum Zeitwertprin- } \\
\text { zip) } \\
\text { - Währungsrisiken } \\
\text { - Risiken aus Termin-, Options- und Swap-Geschäften }\end{array}$} \\
\hline Vorgehen & $\begin{array}{l}\text { - Unterbewertung der } \\
\text { - Wertpapiere der Liquiditätsreserve so- } \\
\text { wie der } \\
\text { - Forderungen an Kunden und } \\
\text { - Forderungen an Kreditinstituten } \\
\text { - Bildung einer stillen Reserve in Höhe } \\
\text { der Unterbewertung } \\
\text { - Aktivische Absetzung der Vorsorge- } \\
\text { wertberichtigung von den entsprechen- } \\
\text { den Aktivposten in der Bilanz } \\
\text { - Verringerung des Jahresüberschusses }\end{array}$ & $\begin{array}{l}\text { aus der Bilanz und der GuV- } \\
\text { Rechnung ersichtliche Einstel- } \\
\text { lung in die Passivposition: } \\
\text { „Fonds für allgemeine Bankri- } \\
\text { siken“ } \\
\text { zu Lasten des versteuerten Ge- } \\
\text { winns }\end{array}$ \\
\hline \begin{tabular}{|l|} 
Unter- \\
und Ober- \\
grenze
\end{tabular} & $\begin{array}{l}\text { maximal } 4 \% \text { der nach strengem Nie- } \\
\text { derstwertprinzip bewerteten Wertpapiere } \\
\text { der Liquiditätsreserve sowie der Forderun- } \\
\text { gen an Kunden und an Kreditinstituten }\end{array}$ & $\begin{array}{l}\text { - } \text { keine Obergrenze } \\
\text { - erfolgt nach vernünftiger kauf- } \\
\text { männischer Beurteilung } \\
\text { - mindestens } 10 \% \text { der Nettoerträ- } \\
\text { ge aus Finanzgeschäften }\end{array}$ \\
\hline Ausweis & $\begin{array}{l}\text { - kein offener Ausweis der Reserven im } \\
\text { Jahresabschluss } \\
\text { - Vorsorgewertberichtigungen werden } \\
\text { aktivisch von den Vermögenswerten } \\
\text { abgesetzt und mindern somit optisch } \\
\text { das Jahresergebnis/Eigenkapital }\end{array}$ & $\begin{array}{l}\text { - offener Bilanzausweis } \\
\text { - Passivposition: „Fonds für all- } \\
\text { gemeine Bankrisiken“ } \\
\text { - Kernkapital } \\
\text { - in der GuV sind Zuführungen } \\
\text { und Auflösungen gesondert auf- } \\
\text { zuführen }\end{array}$ \\
\hline $\begin{array}{l}\text { steuer- } \\
\text { liche } \\
\text { Anerken- } \\
\text { nung }\end{array}$ & \multicolumn{2}{|c|}{$\begin{array}{l}\text { - die Bildung von Vorsorgereserven mindert nicht den steuerpflichtigen Ge- } \\
\text { winn. } \\
\text { - eine Bildung von Vorsorgereserven erfolgt insofern immer aus dem bereits } \\
\text { versteuerten Gewinn. }\end{array}$} \\
\hline
\end{tabular}

